\title{
Intravenous Somatic Gene Transfer with Antisense Tissue Factor Restores Blood Flow by Reducing Tumor Necrosis Factor-induced Tissue Factor Expression and Fibrin Deposition in Mouse Meth-A Sarcomas
}

\author{
Youming Zhang, ${ }^{*}$ Youhua Deng, ${ }^{*}$ Thoralf Wendt, ${ }^{\star}$ Birgit Liliensiek, ${ }^{*}$ Angelika Bierhaus, ${ }^{\star}$ Johannes Greten, ${ }^{\star}$ Wei He, ${ }^{\S}$ \\ Baosheng Chen, $\$$ Viola Hach-Wunderle, ${ }^{*}$ Rudiger Waldherr, ${ }^{\star}$ Reinhard Ziegler, ${ }^{\star}$ Daniela Männel, David Mark Stern, ${ }^{\natural}$ \\ and Peter Paul Nawroth* \\ *Departments of Medicine and Pathology, University of Heidelberg, Heidelberg, Germany; ${ }^{\ddagger}$ Department of Internal Medicine IV, \\ University of Jena, Jena, Germany; ${ }^{\S}$ Departments of Molecular Biology and Pathology, Institute of Basic Medical Science Research, \\ Medical Science Academy of China, Beijing, China; "Institute of Pathology/Tumor Immunology, University of Regensburg, Regensburg, \\ Germany; and "Department of Physiology, Columbia University, New York 10027
}

\begin{abstract}
Fibrin is deposited on the endothelial cell surface in the vasculature of murine methylcholanthrene A-induced sarcomas after injection of tumor necrosis factor (TNF). Capillary endothelial cells of the tumor vascular bed become positive for tissue factor after TNF injection, based on immunocytochemistry and in situ hybridization. Intravascular clot formation was not dependent on tissue factor derived from tumor cells, since in vessels of tumors not expressing tissue factor, TNF also induced fibrin/fibrinogen deposition. However, the time course of fibrin/fibrinogen deposition after TNF differed in tumors expressing no, little, or greater amounts of tissue factor. Fibrin/fibrinogen deposition was more rapid in tumors in which the neoplastic cells expressed tissue factor than in tumors not expressing tissue factor. In the tumors not expressing tissue factor, activation of coagulation was dependent on TNF-induced synthesis of tissue factor by host cells, i.e., endothelium or monocytes/macrophages. Intravenous somatic gene transfer with tissue factor cDNA in the antisense orientation (but not sense or vector alone) reduced intravascular fibrin/fibrinogen deposition and restored blood flow to the tumor, showing that de novo tissue factor expression is central in TNF-induced activation of the coagulation mechanism. (J. Clin. Invest. 1996. 97:2213-2224.) Key words: tissue factor • endothelium • gene transfer
\end{abstract}

\section{Introduction}

Tissue factor is the physiologic initiator of coagulation in vivo $(1,2)$. Exposure of tissue factor in subcutaneous tissues to Factor VII/VIIa initiates the procoagulant pathway leading to hemostasis, as demonstrated by the inhibitory effect of an antibody against tissue factor and the bleeding defect in Factor

Address correspondence to Dr. P. Nawroth, Med. I, Bergheimer Str. 58, D 69115 Heidelberg, Germany. Phone: 6221-565618 or 568606; FAX: 6221-563646.

Received for publication 17 October 1994 and accepted in revised form 13 February 1996.

J. Clin. Invest.

(C) The American Society for Clinical Investigation, Inc.

0021-9738/96/05/2213/12 \$2.00

Volume 97, Number 10, May 1996, 2213-2224
VII-deficient individuals (3). Although tissue factor is the presumed trigger for intravascular coagulation and thrombosis, the cellular source and localization of tissue factor has been more difficult to dissect. A probable role for tissue factor in intravascular coagulation and the lethal outcome in septicemia has been suggested by the protective effect of anti-tissue factor antibodies (4).

An important question concerning the potential role of tissue factor in intravascular fibrin formation concerns its expression by the endothelium. In vitro studies have demonstrated inducible expression of tissue factor apoprotein and procoagulant activity in cultured endothelial cells derived from both large and small vessels in response to a range of mediators, such as tumor necrosis factor (TNF) or interleukin 1 (5-9). In contrast it has been more difficult to determine whether endothelial cells express tissue factor while still in their vascular microenvironment (10-12). Studies of tissue factor expression in baboons subjected to Escherichia coli infusion displayed endothelial cell tissue factor only in the splenic microvasculature (13). This has led to the hypothesis that tissue factor expression in intact vessels is closely regulated by environmental factors (14-16).

Tumor vasculature is known for its thrombogenic properties. This is especially true for transplantable murine methylcholanthrene A-induced fibrosarcomas (Meth-A), ${ }^{1}$ in which the first detectable local response to infused TNF is fibrin formation on the endothelium of the tumor bed (15). This suggested the possibility that after administration of TNF, tumor microvasculature might express tissue factor which could then, on exposure to blood, trigger reactions leading to fibrin deposition.

Our study demonstrates that systemic infusion of TNF induces tissue factor in endothelium. Furthermore, tissue factor induction is critical for thrombosis and the dramatic fall in blood flow in the tumor bed, setting the stage for subsequent ischemic thrombohemorrhage. Using tumor cells genetically engineered to express virtually no tissue factor, we show that it is not only tumor cell tissue factor but also host cell tissue factor which are critical to TNF-induced fibrin deposition and reduction in blood flow in the tumor. Using intravenous somatic gene transfer with an expression plasmid containing tissue factor cDNA in the antisense orientation, we show that fibrin/fibrinogen deposition and diminished blood flow after adminis-

1. Abbreviations used in this paper: Meth-A, methylcholanthrene A; TAT, thrombin-antithrombin III complexes. 
tration of TNF are due to cytokine-mediated induction of tissue factor transcription and translation.

\section{Methods}

Expression vectors. The pXT1 expression vector (Stratagene, Heidelberg, Germany) was used for constructing the tissue factor expression system (17-20). Murine tissue factor cDNA was generously provided by Dr. Nathans (21). The full-length tissue factor cDNA was inserted into pXT1 from $3^{\prime}$ to $5^{\prime}$ for the tissue factor antisense construct (pXTF-as) or from $5^{\prime}$ to $3^{\prime}$ for the tissue factor sense construct (pXTF-s) (17). As control, a truncated form of tissue factor (from 225 to $1,800 \mathrm{bp}$ ) missing the ATG start codon was cloned in pXT1 (17). Transfection with $\mathrm{pXTF}$-ts does not result in expression of tissue factor protein (17). pSV- $\beta$-galactosidase (pSV- $\beta$-gal), control vector, and pGL2-luciferase (pGL2-luc) vector were obtained from Promega (Heidelberg, Germany).

Cell culture and characterization of stable transfectants. To study the role of tumor cell-derived tissue factor in TNF-mediated fibrin formation, we prepared stably transfected tumor lines, which differed in the amount of tissue factor (17). The cell lines have been described previously (17). In vitro transfection was performed using the liposome method (22) as described previously (17). The cell lines used were derived from 3-5 $\times 10^{3}$ colonies each. Selected stable transfectants have been described previously (17). They were characterized by one-stage clotting assay $(8,23)$, Southern blotting (24), Northern blotting $(9,25)$, nuclear run-on $(9,26)$, Western blotting $(17)$, growth in vivo and in vitro (17), and immunocytochemistry $(17,27)$. For the experiments shown, stable transfected cell lines from at least three independent transfections were used with similar results. The following transfectants were obtained, which were characterized with respect to tissue factor activity (17): (a) pXTF-as, full-length tissue factor cDNA in the antisense orientation, blocking tissue factor expression $(\sim 5 \mathrm{U} /$ $10^{5}$ cells); (b) pXTF-s, full-length tissue factor cDNA in the sense orientation, leading to overexpression of tissue factor $\left(\sim 1,100 \mathrm{U} / 10^{5}\right.$ cells); (c) pXTF-ts, tissue factor cDNA lacking ATG start codon; and (d) pXT1, vector alone. The last two transfectants expressed tissue factor comparable with wild-type cells $\left(\sim 100 \mathrm{U} / 10^{5}\right.$ cells $)$.

Tumor growth in vivo. To examine the role of tissue factor in TNF-mediated intravascular fibrin/fibrinogen deposition in vivo, $\mathrm{C}_{3} \mathrm{H}$ mice were injected intradermally with stably transfected Meth-A sarcoma cells $\left(10^{6}\right.$ cells/animal) (17). Four different cell lines (as, s, ts, and $\mathrm{v}$ ) were implanted.

Intravenous somatic gene transfer. To study the significance of host cell tissue factor expression, intravenous somatic gene transfer in mice bearing tumors from stably transfected Meth-A cells not expressing tissue factor was used. For in vivo intravenous transfection, DNA-liposome complexes were mixed as follows: $100 \mu \mathrm{g}$ of plasmid DNA (murine tissue factor expression plasmid) was added to $600 \mu \mathrm{g}$ LipofectAMINETM which contains 3:1 liposome formulation of the cationic lipid $N$-[2-(\{2,5-bis[(3-aminopropyl)amino]-1-oxypentyl\}amino) ethyl]- $N, N$-dimethyl-2,3-bis(9-octadecenyloxy)-1-propanaminium trifluoroacetate and dioleoyl phosphatidylethanolamine in membranefiltered water (GIBCO BRL, Eggenstein, Germany). The following plasmids were used for intravenous somatic gene transfer: pXTF-as, pXTF-s, pXTF-ts, pXT1 (the same plasmids as described in reference 17), pSV- $\beta$-gal (Promega), and pSVL2-luc (Promega).

The mice (18-20 grams) were injected intravenously via the tail vein with DNA-liposome complexes on the same day the Meth-A sarcomas were implanted. A second injection with DNA was performed $2 \mathrm{~d}$ before treatment of the animals with TNF (15). When the tumors reached a size of $\sim 1 \mathrm{~cm}$ in diameter (usually $12-14 \mathrm{~d}$ after the first injection of DNA), mice were injected intravenously via the tail vein with TNF (5 animals). With stable expression of tissue factor in the tumor transfectants, which was not altered by TNF or intravenous gene transfer (data not shown), we were able to control tissue factor expression in the mouse host cells by intravenous somatic gene transfer.
Mice were killed after TNF injection at the time point indicated in the figure legends.

Luciferase assay. $2 \mathrm{~d}$ after the last injection of luciferase DNA plus Lipofectin, tumors, lung, heart, liver, spleen, and kidney were harvested and weighed. Organs were homogenized in lysis buffer (Promega) for $1 \mathrm{~min}$. After centrifugation, the supernatant was collected. The luciferase assay system kit from Promega was used for luciferase assay $(28,29)$ and determination of in vivo gene transfer efficiency. Luciferase activity was measured in a luminometer (LB 9501; Lumat, Berthold, Germany). The data are expressed as luciferase activity per gram of tissue.

Determination of thrombin-antithrombin III complexes (TAT). Tumors were cut into 100-mg pieces, mixed with $250 \mu \mathrm{l}$ lysis buffer (25 mM Tris-phosphate, $\mathrm{pH}$ 7.8; 2 mM DTT; 2 mM 1,2-diaminocyclohexane- $N, N, N^{\prime}, N^{\prime}$-tetraacetic acid; $10 \%$ glycerol, and Triton X-100), and homogenized. $50 \mu \mathrm{l}$ of the supernatant was used to measure TAT. The TAT assay was performed according to the manufacturer's instructions (Behring, Marburg, Germany).

Determination of blood flow. For the measurement of blood flow in mice, E-Z Trac Ultraspheres ${ }^{\mathrm{TM}}$ (E-Z Trac, Inc., West Los Angeles, CA) were used. Briefly, $5 \times 10^{5}$ colored microspheres were injected into the left ventricle of the anesthetized mouse over 10-20 s with 1 $\mathrm{ml}$ of PBS. The tumors were harvested and weighed. Then, $4 \mathrm{ml}$ of 1:1 diluted tissue/blood digest reagent I (E-Z Trac), a strong alkaline solution, was added to each sample. The tubes containing tumor tissues were placed in a heated water bath at $80^{\circ} \mathrm{C}$ to hydrolyze the tumors overnight. The next day, the tubes with tightened screw caps were vigorously vortexed for $\sim 30-60 \mathrm{~s}$, until the tissue was completely homogenized, with only small particles of fatty white debris visible. Diluted tissue/blood digest reagent II (E-Z Trac) was added to the sample suspension to bring the total liquid volume to $14-15 \mathrm{ml}$. After mixing by inversion, the tubes were centrifuged for $30 \mathrm{~min}$ at $1,500 \mathrm{~g}$ and the supernatant was aspirated to a level slightly above each pellet. Each greenish-brown sediment was resuspended in $10 \mathrm{ml}$ of diluted microsphere counting reagent (E-Z Trac). After centrifugation for $15 \mathrm{~min}$ at $1,500 \mathrm{~g}$, the supernatant was aspirated to a level slightly above the visible pellet. The pellet was suspended in $100 \mu \mathrm{l}$ counting reagent, and $10 \mu \mathrm{l}$ of thoroughly mixed solution was used for counting. The number of colored microspheres in the final tissue preparations was determined using a hemocytometer counting slide (17).

Generation and characterization of the monoclonal rat anti-mouse tissue factor antibody. Female Lewis rats (10-14 wk old) were obtained from the animal facility of the Max-Planck-Institute of Immunobiology (Freiburg, Germany). Animal care was in accordance with institutional guidelines. All invasive procedures were performed after the animals had been anesthetized by intraperitoneal injection of Ketanest ( $25 \mathrm{mg} / \mathrm{gram}$; Parke, Davis and Co., Munich, Germany) and Rompun (5 mg/gram; Bayer AG, Leverkusen, Germany).

The rats were immunized with mouse tissue factor fusion protein, which was also used for screening in the ELISA system. It was prepared and purified as described before (17). Briefly, the fusion protein expression vector pMAL-c2 (New England Biolabs Inc., Beverly, MA) was used for expressing mouse tissue factor. Full-length mouse tissue factor cDNA was inserted into the vector and the reading frame of the mouse tissue factor was matched with the vector reading frame. The expressed fusion protein was purified according to the protocol of the protein fusion and purification system kit (New England Biolabs Inc.). The fusion protein $(5 \mathrm{mg})$ was dried onto a small piece of nitrocellulose and implanted into the spleens of the rats as described $(30,31)$.

The rats were bled under narcosis from the retroorbital plexus and serum was prepared. Serial dilutions of the sera and later the hybridoma supernatants were tested for the presence of antibodies in ELISA systems. Wells of ELISA plates (Becton Dickinson Advanced Cellular Biology, San Jose, CA) were coated with the mouse tissue factor fusion protein $(5 \mathrm{mg} / \mathrm{ml})$ in coating buffer $(50 \mathrm{mM}$ $\mathrm{NaHCO}_{3}, \mathrm{pH} 9$ ) overnight at $4{ }^{\circ} \mathrm{C}$, blocked with $10 \%$ low-fat dry milk powder (Meister, Regensburg, Germany) for $2 \mathrm{~h}$ at room tempera- 
ture and subsequently after washing with PBS/Tween (0.02\%) exposed to the antibody samples (containing $1 \%$ milk powder) for $1 \mathrm{~h}$ at room temperature. For detection alkaline phosphatase-conjugated rabbit anti-rat $\operatorname{IgG}$ (1:1,000 diluted) (Sigma Chemie, Deisenhofen, Germany) in $1 \%$ milk powder was used for $1 \mathrm{~h}$ at room temperature. The enzyme was visualized after washing with PBS/Tween $(0.02 \%)$ with paranitrophenylphosphate (104-0 substrate, $30 \mathrm{mg} / 50 \mathrm{ml}$; Sigma Chemie) in diethanolamine buffer ( $96 \mathrm{ml}$ diethanolamine/liter, $49 \mathrm{mg}$ $\mathrm{MgCl}_{2} /$ liter, $\mathrm{pH}$ 9.8) and absorption read on an ELISA reader (MWG Biotech, Ebersberg, Germany) at $405 \mathrm{~nm}$.

As a second screening method a cell ELISA was established using the mouse fibrosarcomas (CFS-1) stably transfected with tissue factor sense (pXTF-s) or antisense (pXTF-as), respectively, as described above (17). Cells $\left(10^{6} /\right.$ well) were seeded into 96-well tissue culture plates and cultured overnight. The wells were washed with PBS/ Tween $(0.02 \%)$, blocked with PBS/Tween $(0.02 \%)$, BSA ( $1 \%)$ for 30 min at $37^{\circ} \mathrm{C}$, washed again and incubated with the antibody samples for $45 \mathrm{~min}$ at $37^{\circ} \mathrm{C}$. After washing five times with $\mathrm{PBS} / \mathrm{Tween}$ $(0.02 \%)$, horse radish peroxidase-coupled goat anti-rat IgG $(1: 10,000$ diluted with PBS/Tween [0.02\%], BSA [1\%]) (Sigma Chemie) was added for $30 \mathrm{~min}$ at $37^{\circ} \mathrm{C}$. The enzyme was visualized after washing five times with $\mathrm{PBS} /$ Tween $(0.02 \%)$ with ABTS (2,2\{-azino-di-(3ethyl-benzthiazolin-sulfate)\}) (Boehringer Mannheim, Mannheim, Germany), $1 \mathrm{mg} / \mathrm{ml}$ ABTS buffer (Boehringer Mannheim), and absorption read at $405 \mathrm{~nm}$.

From one fusion, 48 hybridomas were obtained that were positive in the tissue factor fusion protein ELISA, of which 27 were also positive in the cell ELISA (i.e., reacting positive with tissue factor sense, but not with tissue factor antisense transfectants). Further screening determined seven hybridomas producing antibodies inhibiting the one stage clotting assay (23) and eight being able to specifically recognize the tissue factor protein and tissue factor in the extracts from mouse skin in Western blotting. The supernatant from these clones was also tested in Western blots of tumor extracts derived from stable transfected Meth-A cells.

Immunocytochemistry. For immunocytochemistry staining, tumors were harvested after the animal had been perfused with $30 \mathrm{ml}$ of PBS to remove unclotted material and instantaneously frozen in isopentan, cooled in liquid $\mathrm{N}_{2}(32,33)$. After cutting, sections were fixed in $4 \%$ paraformaldehyde in $1 \times$ PBS for $20 \mathrm{~min}$ and washed three times for $10 \mathrm{~min}$ with $1 \times$ PBS. The sections were incubated with the first antibody (rabbit anti-human von Willebrand factor; Sigma Chemical Co., St. Louis, MO) for $2 \mathrm{~h}$ at room temperature in buffer I (100 mM Tris-HCl, pH 7.5, $150 \mathrm{mM} \mathrm{NaCl}, 0.3 \%$ Triton X-100). Then the sections were washed three times with buffer I without Triton and incubated with the second antibody (goat anti-rabbit IgG conjugated with alkaline phosphatase; Sigma Chemical Co.) for $60 \mathrm{~min}$ at room temperature $(32,33)$. After washing the sections as above, the color was developed by NBT and BCIP in buffer II (100 mM Tris-HCl, $\mathrm{pH}$ 9.5, $100 \mathrm{mM} \mathrm{NaCl}$, and $50 \mathrm{mM} \mathrm{MgCl} 2$ ). After the color appeared, sections were treated with $95 \%$ ethanol for $10 \mathrm{~min}$.

The stained sections were counterstained with monoclonal antimouse tissue factor antibody (rat anti-mouse) for $2 \mathrm{~h}$ at room temperature in buffer I with Triton. After washing, the sections were incubated with the second antibody (goat anti-rat IgG conjugated with peroxidase) for $1 \mathrm{~h}$ at room temperature. The red color was developed with AEC (3-amino-9-ethyl-carbazole; Sigma Chemical Co.) and $\mathrm{H}_{2} \mathrm{O}_{2}$ (34)

Negative controls for immunohistochemistry included omission of first or second antibody, or substitution of first antibody by an anti-human tissue factor antibody not cross-reacting with mouse tissue factor. Furthermore, we could prevent a reaction of the antibody against recombinant mouse tissue factor by addition of excess amounts of recombinant tissue factor (but not another bacterial protein) to the antibody before incubation with the tissue section (data not shown).

Monoclonal anti- $\beta$-galactosidase antibody was obtained from Promega and the staining method is the same as for tissue factor staining.

Immunofluorescence. For immunofluorescence studies the tu- mors were harvested at the desired time points after perfusion with $30 \mathrm{ml}$ of PBS to remove unclotted material. For immunofluorescence staining, antifibrin/fibrinogen antibody (fluorescein conjugate) (Cappel Laboratories, West Chester, PA) was diluted 1:8 with PBS containing $\mathrm{NaN}_{3}$. The tumor sections were fixed with aceton for $10 \mathrm{~min}$. After washing once with PBS, the sections were incubated with diluted antibody for $45 \mathrm{~min}$ at room temperature and then washed three times with PBS. Pictures were taken at a magnification of 40 . The fluorescence was quantitated by densitometry. For determination of fibrin/fibrinogen deposition at different times after TNF in the stably transfected tumors, three cuts derived from each tumor were analyzed. In total, six tumors from three independent experiments were included at each time point. Thus, each point shown in Fig. 3 represents 18 cuts.

In situ hybridization. In situ hybridization was performed as described previously $(35,36)$. Briefly, antisense and sense single-strand cRNAs were synthesized from a mouse tissue factor cDNA fragment (bp 721-1,043) subcloned into pGEM2 (Promega) in the presence of digoxigenin-labeled UTP (Boehringer Mannheim). These probes have been characterized in Northern blots. The antisense riboprobe recognized the correct $2.0-\mathrm{kb}$ band, while the sense probe gave no signal.

The tumor sections were fixed in $4 \%$ paraformaldehyde in PBS, $\mathrm{pH} 7.4$, and acetylated for $15 \mathrm{~min}$ at room temperature in freshly prepared $0.25 \%$ acetic anhydride in $0.1 \mathrm{M}$ triethenolamine $\mathrm{HCl}$ plus $0.9 \% \mathrm{NaCl}, \mathrm{pH} 8.0$, after washing three times with PBS. Then the glass slides were dehydrated with 70,80 , and $95 \%$ ethanol. The sections were prehybridized for $2 \mathrm{~h}$ at room temperature with hybridization buffer contained $0.6 \mathrm{M} \mathrm{NaCl}, 1 \mathrm{mM}$ EDTA, $10 \mathrm{mM}$ Tris $\mathrm{HCl}, \mathrm{pH}$ 7.6, $10 \%$ dextran sulfate, $0.25 \%$ SDS, $100 \mathrm{mM}$ DTT, $50 \mu \mathrm{g} / \mathrm{ml}$ denatured DNA, $100 \mu \mathrm{g} / \mathrm{ml}$ transfer RNA, $1 \times$ Denhardt's solution, $5 \%$ dextran, and $50 \%$ (vol/vol) deionized formamide. After prehybridization, hybridization solution plus 5-10 ng cRNA probe was applied to each section, followed by incubation in a moist chamber for $16 \mathrm{~h}$ at $37^{\circ} \mathrm{C}$. Samples were then incubated with $20 \mu \mathrm{g} / \mathrm{ml}$ RNase A (Boehringer Mannheim) for $30 \mathrm{~min}$ at $37^{\circ} \mathrm{C}$, followed by washing once with $2 \times$ SSC plus $50 \%$ formamide for $30 \mathrm{~min}$ at room temperature, and twice with $0.2 \times$ SSC for $30 \mathrm{~min}$ at room temperature. For immunological detection, DIG nucleic acid detection kit (Boehringer Mannheim) was used according to the manufacturer's instructions. In each section a parallel cut was stained as control with sense riboprobe, which gave no specific signal.

Statistical analyses. All values are given as mean. Bar shows standard deviation (SD). Means of groups were compared with ANOVA using the Newman-Keul's test to correct for multiple comparisons. $P<0.05$ is considered statistically significant.

Reagents. Human TNF $\left(\sim 10^{8} \mathrm{U} / \mathrm{mg}\right)$ was generously provided by BASF (Ludwigshafen, Germany), and this preparation was homogeneous on SDS-PAGE and distinct from lymphotoxin, as described previously (8). TNF was heat inactivated as described previously (8). Heat-inactivated TNF had no biologic effect $(8,15)$.

\section{Results}

It is unknown whether the TNF-mediated fibrin formation in the mouse model (15) depends on tissue factor and what the source of tissue factor might be. The availability of tumor cells not expressing tissue factor (17) provided an opportunity to determine the role of tumor cell tissue factor in TNF-induced tumor thrombosis. To exclude tissue factor synthesis and release by tumor cells as the source for activation of the coagulation mechanism, we used stably transfected Meth-A sarcoma cell mutants published previously (17). The stable antisense tissue factor transfectants were implanted intracutaneously into mice. There was no detectable tissue factor in tumor cells by immunohistochemistry or in situ hybridization. Tumors developed, although smaller and less vascularized than wild-type 
or vector transfectants (17). We studied clot formation in the stable transfectants $4 \mathrm{~h}$ after intravenous TNF injection.

Intravenous administration of TNF (but not heat-inactivated TNF) to animals with tumors established from the antisense transfectants resulted in intravascular fibrin/fibrinogen deposition and clot formation comparable with that seen in wild-type tumors (Fig. 1). Note the large difference in fibrin/fibrinogen deposition after TNF (Fig. 1, top right) compared with control animals not treated with TNF (Fig. 1, top left). Fibrin formation occurred even though the tumor cell transfectants were not capable of expressing tissue factor after TNF. Thus fibrin formation is not exclusively dependent on the amount of tissue factor expressed by tumor cells.

The antisense tumors, not expressing tissue factor, responded to TNF with clot formation (Fig. 1, bottom left, control; bottom right, after TNF). When fibrin/fibrinogen deposition and clot formation were compared in tumors arising from the different stable transfectants, we found that clots formed in all tumor lines tested, even in the antisense tissue factor trans- fectants shown in Fig. 1. TNF did not alter the tissue factor expression in tumor cells stably transfected with tissue factor cDNA in the antisense orientation (17). Hence, fibrin/fibrinogen deposition and clot formation were not due to TNF-mediated alteration in the tissue factor expression of tumor cells.

The number of clots observed per section was highest in the sense transfectants. Since sense transfectants expressing the highest amount of tissue factor grow the largest and are the most vascularized tumors (17), we evaluated the number of clots observed in relation to the number of microvessels identified in serial sections. When serial sections of the different tumor lines were analyzed, we found no statistically significant difference in the number of clots formed after TNF in relation to the number of vessels. Thus, the higher incidence of clots observed in the sense transfectants and the lower number of clots observed per section in the antisense transfectants can be explained by differences in vascularization.

To establish that TNF infusion indeed leads to a drop of blood flow independent of the tumor cell tissue factor content,

\section{Control}
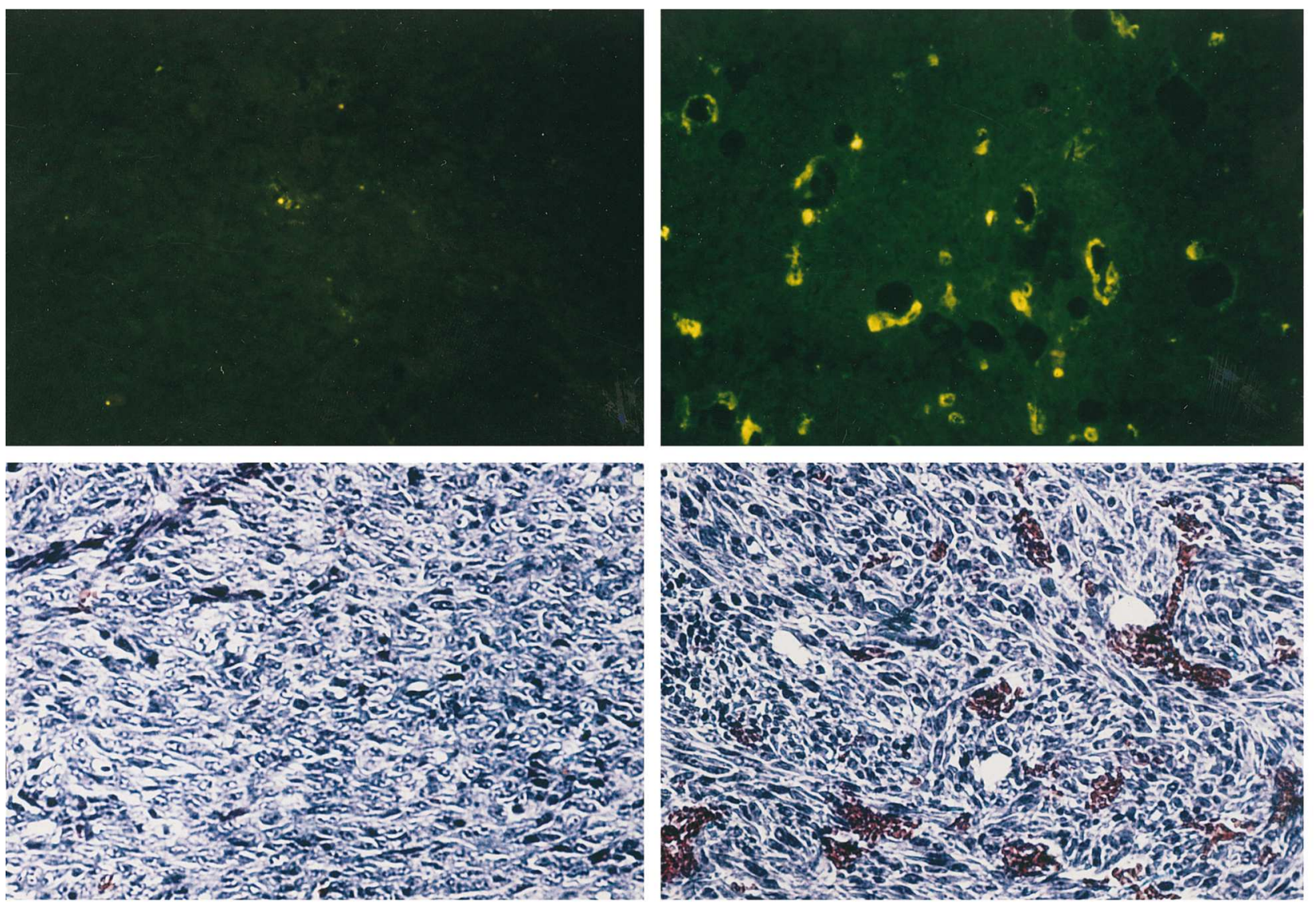
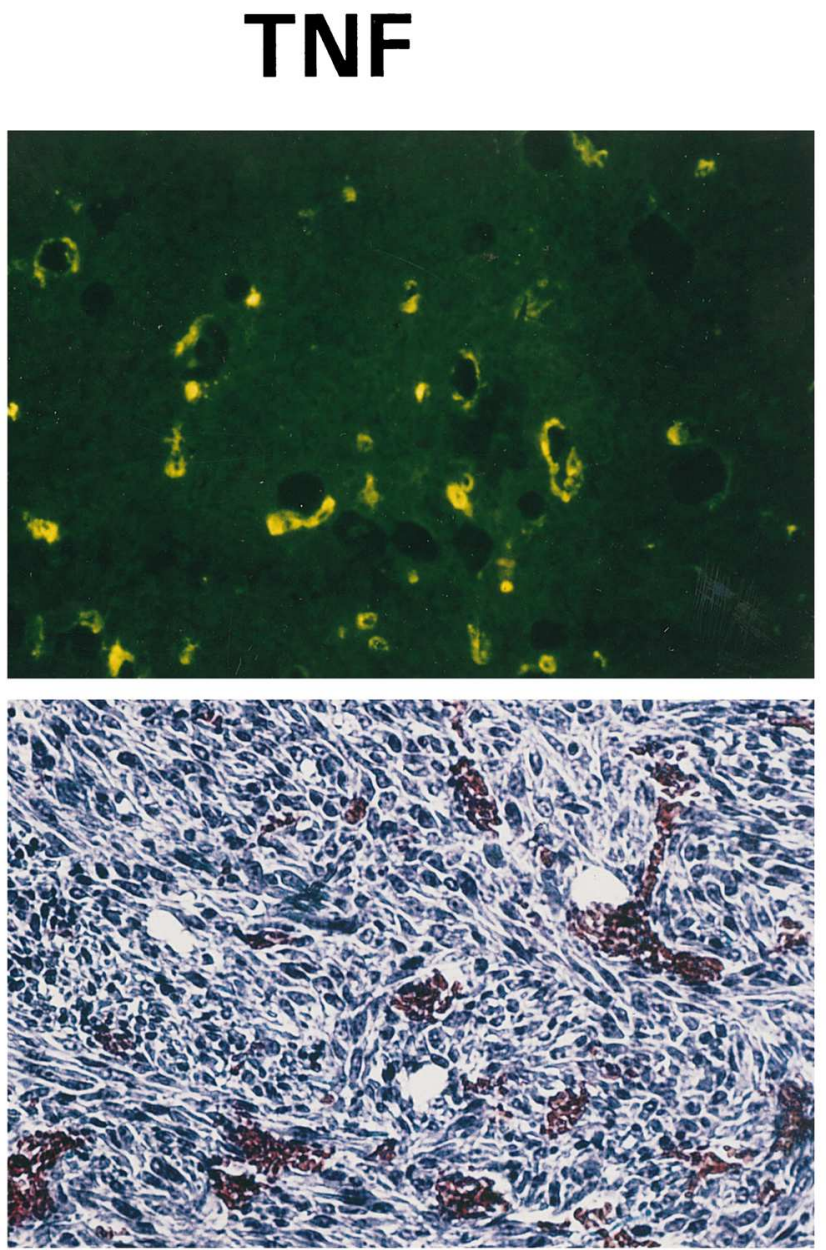

Figure 1. TNF induces fibrin formation (top) and clot formation (bottom) in tumors derived from stable antisense tissue factor transfectants. Tumors not expressing tissue factor were harvested from mice treated with PBS alone (left) and mice $3 \mathrm{~h}$ after treatment with $5 \mu \mathrm{g}$ TNF (right). Before harvest, animals were perfused with $30 \mathrm{ml}$ PBS to remove nonclotted immunoreactive material. (Top) Fibrin/fibrinogen deposition in control animals $(l e f t)$ and TNF-treated animals $($ right $)$ was evidenced by immunofluorescence, $\times 40$. When compared with control animals $(l e f t)$, TNF (right) induced fibrin/fibrinogen deposition in the tumors not able to express tissue factor. (Bottom) Clot formation shown by Misson trichrome staining in tumors of control animals (left) was not observed, while after TNF, even in tumors not able to express tissue factor, clots were found $($ right $), \times 40$. The experiment has been repeated three times with similar results. Fibrin/fibrinogen deposition and clot formation were identical in serial sections of each tumor studied. 
we studied the tumor perfusion with a latex bead system (17). When the number of beads in animals treated with TNF (Fig. 2, white bars) was compared with animals not treated with TNF (Fig. 2, black bars), a drastic drop of free blood flow, as evidenced by the lower number of beads per gram tumor tissue, was seen. In all stable transfected tumor lines tested, a drop in blood flow was demonstrated. The drop in blood flow was strongest in the sense tumors, which is explained by the higher vascularization of the sense tumors and the lower vascularization of the antisense tumors (17).

Therefore, tissue factor released from the implanted tumor cells is not necessary for TNF-mediated intravascular fibrin/fibrinogen deposition, clot formation, and drop in free blood flow after TNF in this animal model. However, TNF is known to enhance vascular permeability, thus making "cryptic" tissue factor in subendothelium available to interact with components of plasma. If this were true, then TNF-mediated fibrin/fibrinogen deposition in tumors expressing tissue factor should occur faster than in tumors not capable of expressing tissue factor. To test this, fibrin/fibrinogen deposition was quantitated by densitometry at different time points after administration of TNF (Fig. 3). For these experiments mice were perfused extensively with PBS to wash out nonclotted material. In tumors expressing tissue factor, fibrin/fibrinogen deposition occurred earlier than in tumors not expressing tissue factor. Thus, the TNF-induced fibrin/fibrinogen deposition is not dependent on tumor cell tissue factor. However, the rate at which fibrin/fibrinogen deposition occurs is faster in tumors expressing tissue factor than in antisense transfectants.

$T N F$ induces expression of tissue factor in endothelial cells. Endothelial cell expression of tissue factor was determined using a monoclonal antibody against murine tissue factor (red staining) and a polyclonal antibody against von Willebrand factor (blue staining) in mice treated by intravenous somatic

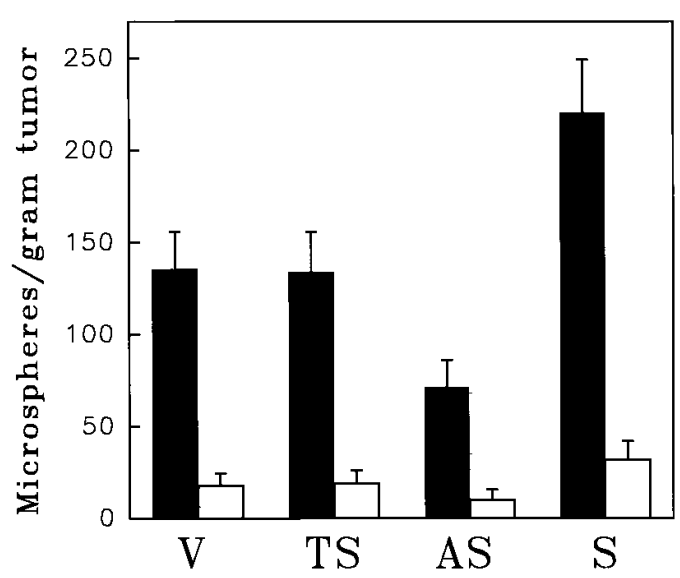

Figure 2. TNF-mediated drop in free blood flow is independent of the tumor cell tissue factor expression. Mice were intracutaneously injected with $10^{6}$ tumor cells (stable transfectants with tissue factor antisense, $A S$; vector alone, $V$; truncated sense, $T S$; or sense, $S$ ). After $12 \mathrm{~d}$ the mice were anesthetized and latex microbeads were injected into the left ventricle (see Methods). Shown is the free blood flow, evidenced by the number of latex particles per gram of tumor tissue in animals treated with PBS alone (black bars) and animals $3 \mathrm{~h}$ after intravenous injection of $5 \mu \mathrm{g}$ TNF (white bars). Note that the TNF-mediated decrease in free blood flow is independent of the tissue factor content of the tumors cells. $n=10$.

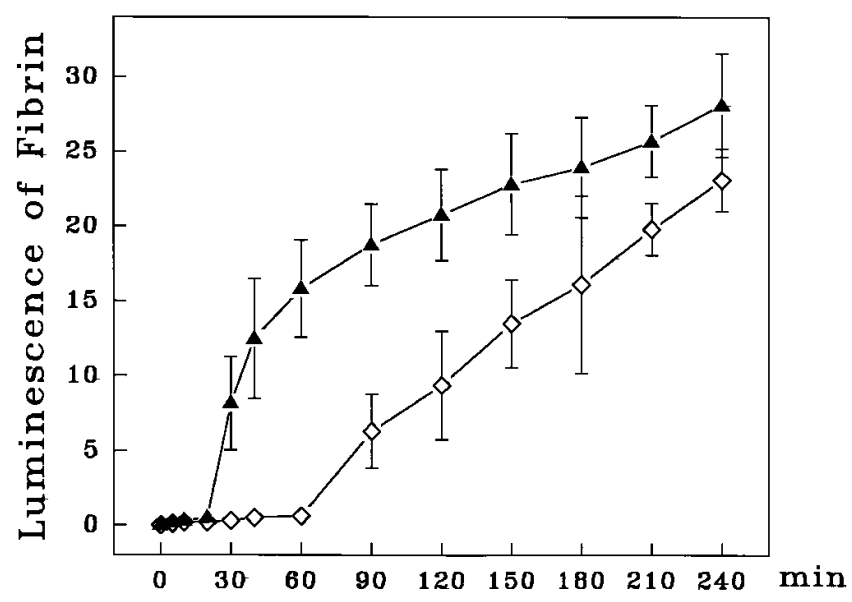

Time Points after TNF Treatment

Figure 3. Time course of TNF-mediated fibrin/fibrinogen deposition. Mice were intracutaneously injected with $10^{6}$ tumor cells (stable transfectants with tissue factor antisense, white diamonds, and sense, black triangles). After $12 \mathrm{~d}$ the mice were anesthetized and perfused with $30 \mathrm{ml}$ of PBS at the indicated time points after injection of $5 \mu \mathrm{g}$ TNF. Three sections from each tumor were stained for fibrin/fibrinogen deposition. Each point represents 18 sections from six tumors from three independent experiments. The amount of fluorescence was quantitated by densitometry. Each point represents mean \pm SD. $n=18$.

gene transfer (see below) with vector as control (Fig. $4 a$, middle). Gene transfer with vector alone does not influence tissue factor expression (17).

Immunostaining of tumors revealed that the capillary endothelial cells became more positive for tissue factor antigen after intravenous administration of TNF (Fig. 4a, right middle) compared with PBS-treated animals (Fig. 4 a, left middle). Tissue factor positivity was most prominent in capillaries, while the large venules and arterioles showed only occasional positivity.

Reaction of tissue sections with preimmune IgG or saturation of anti-tissue factor antibody with recombinant tissue factor antigen showed no specific staining pattern. Although TNF was infused systemically, mainly endothelium in tumor vessels demonstrated consistent and striking tissue factor expression. Only weak tissue factor positivity was found in the endothelium of other organs (kidney). Heat-inactivated TNF had no effect on the expression of tissue factor.

Tissue factor in the endothelium of the neovasculature was likely to result from de novo synthesis as in situ hybridization with an antisense tissue factor riboprobe demonstrated presence of the mRNA (Fig. $4 b$, middle). No reaction was seen when sense probe was used (data not shown).

The data shown in Fig. 4 are from an antisense transfected tumor, expressing virtually no tissue factor. The same results have been obtained with tumor cells stably transfected with tissue factor sense, truncated sense, or vector alone. Therefore, host capillary endothelial cells are capable of responding to TNF by increased transcription and translation of tissue factor.

Establishment of intravenous somatic gene transfer. Since the effect of TNF was not only dependent on tissue factor expression of tumor cells (Fig. 1-4), it is more likely that a factor induced by TNF in host cells (endothelial cells or circulating cells, i.e., monocytes) is responsible for the activation of the coagulation mechanism. To test this, it was necessary to de- 

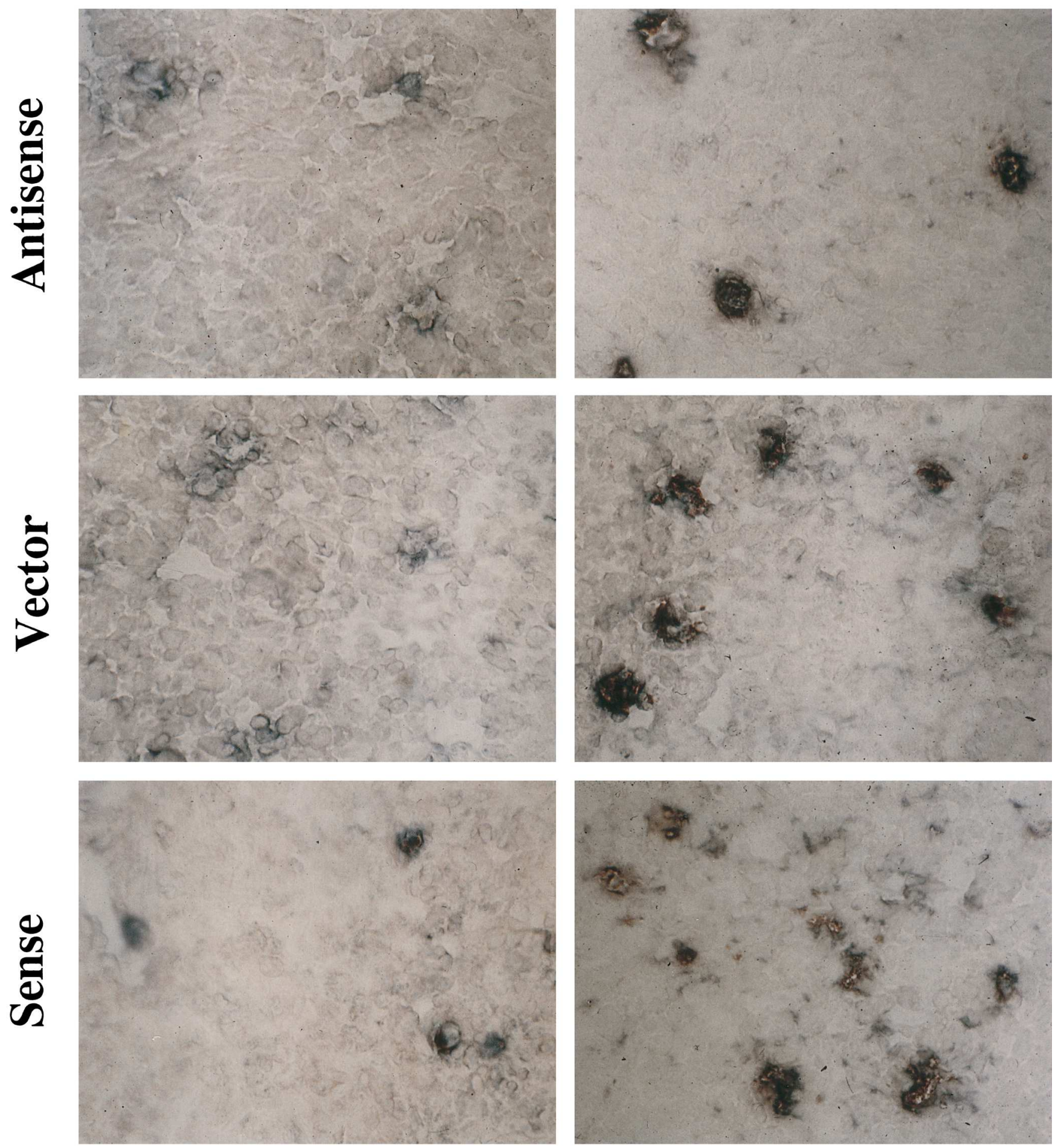

Figure 4. Intravenous somatic gene transfer with tissue factor expression plasmids allows for control of the endothelial cell response to TNF. Mice were implanted with stable Meth-A sarcoma transfectants not able to express tissue factor (antisense transfectants). After the tumor reached a size of $0.5 \mathrm{~cm}$ intravenous somatic gene transfer was performed with the expression plasmids containing tissue factor cDNA (see Methods). On the left side are the results of mice treated with PBS alone, on the right side are mice treated for $3 \mathrm{~h}$ with $5 \mu \mathrm{g}$ TNF. The first row in each part of the figure shows the result of mice pretreated by intravenous somatic gene transfer with the plasmid containing tissue factor in the antisense orientation, the middle row with vector alone, and the bottom row pretreatment with the expression plasmid containing tissue factor in the sense orientation. Shown are tumor vessels from serial sections of at least four tumors from six independent experiments. Immunohis-

tochemistry, in situ hybridization, and immunofluorescence were performed as described in Methods (immunohistochemistry and in situ hybridization, $\times 160$; immunofluorescence, $\times 40$ ). (a) Immunohistochemistry of von Willebrand factor (blue) and tissue factor (red). (b) In situ hybridization with the tissue factor antisense riboprobe. (c) Immunofluorescence of fibrin/fibrinogen deposition. 


\section{b}
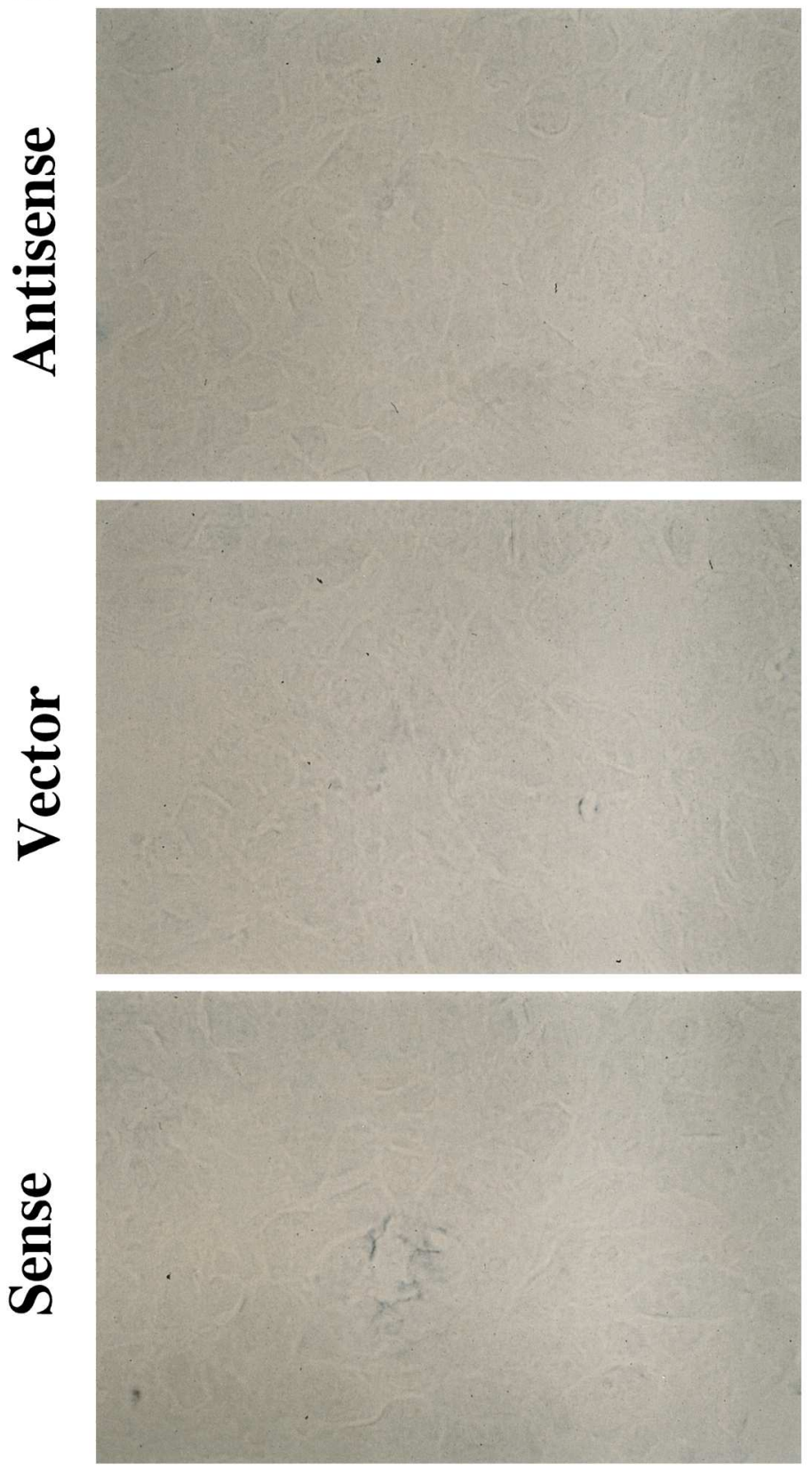

velop a system to specifically control tissue factor expression in host cells.

To establish intravenous somatic gene transfer in our system, studies were performed with plasmids expressing luciferase packed in Lipofectin (see Methods). After intravenous administration on days 2 and 7 of the experiment, luciferase activity was determined on day 9 (Fig. $5 a$ ). Luciferase activity was observed in a range of organs (expressed as activity per gram of protein). Using this method the optimal DNA/Lipofectin ratio and the optimal sequence of injections were determined (not shown). The tumor tissue expressed slightly more luciferase per gram of tissue than the other organs. A control plasmid lacking a functional promoter was used as control and showed very low background (Fig. $5 a$, lane $g$ ).

\section{TNF}
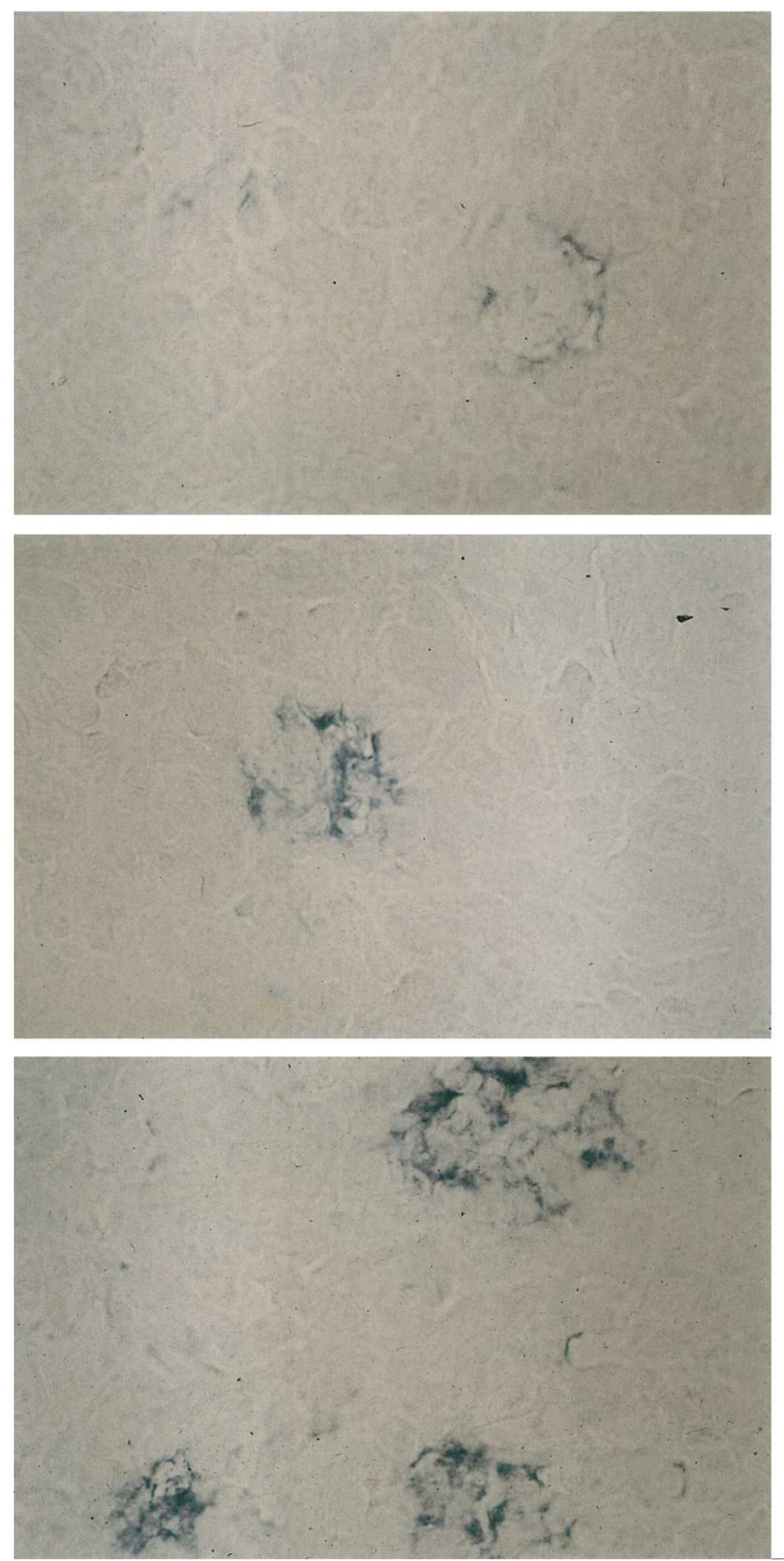

A further set of studies was performed to identify the vascular cells transfectable by intravenous somatic gene transfer. The plasmid pSV- $\beta$-galactosidase packaged in LipofectAMINE $^{\mathrm{TM}}$ was infused intravenously and $\beta$-galactosidase expression was evident in tumor endothelial cells (Fig. $5 b$ ). Expression was still evident when the infusion of TNF was done, hence it lasted throughout the period necessary for the experimental design.

Fibrin formation in vivo is tissue factor dependent. After establishment of a method for intravenous somatic gene transfer of the host, including the host cells forming the tumor vasculature, we tested whether intravenous gene transfer with expression plasmids bearing antisense or sense tissue factor cDNA or control vector alone would result in modulation of tissue factor 


\section{Control}
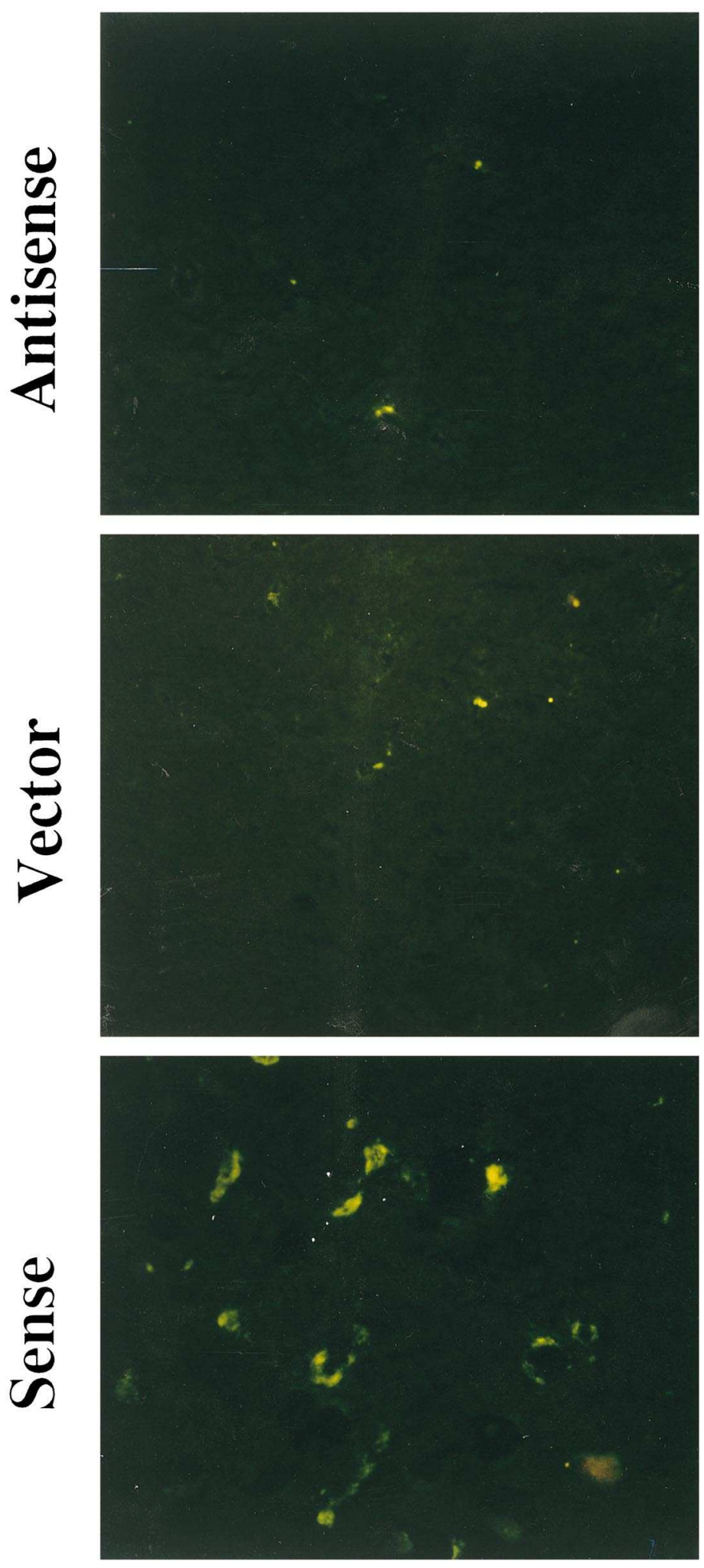

\section{TNF}
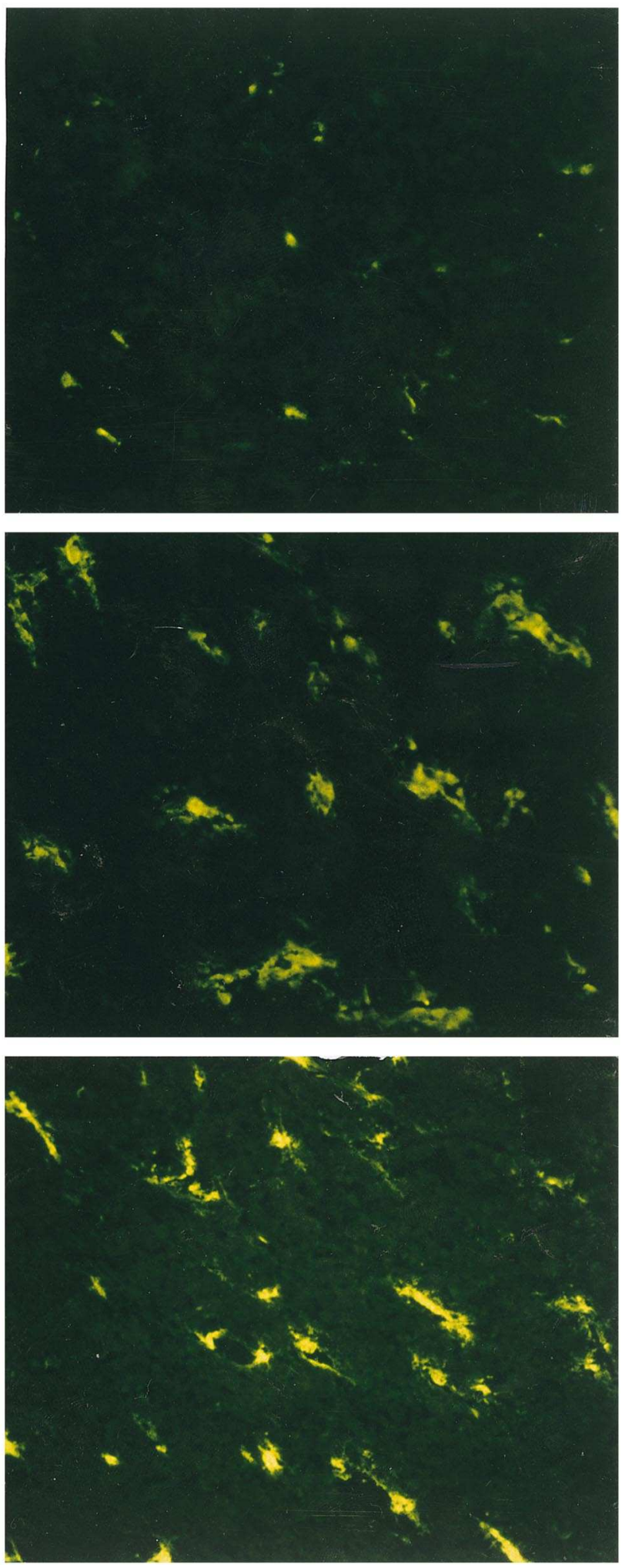

induction and fibrin/fibrinogen deposition in response to TNF.

When the expression plasmid containing tissue factor cDNA in the antisense orientation or vector alone was injected in animals not infused with TNF (Fig. 4, $a$ and $b$, top left and middle left), weak or no tissue factor staining (red) was observed, compared with sense-treated animals (Fig. 4, $a$ and $b$, bottom left). When the antisense tissue factor-pretreated mice were infused with TNF (Fig. 4, $a$ and $b$, top right), there was al- 


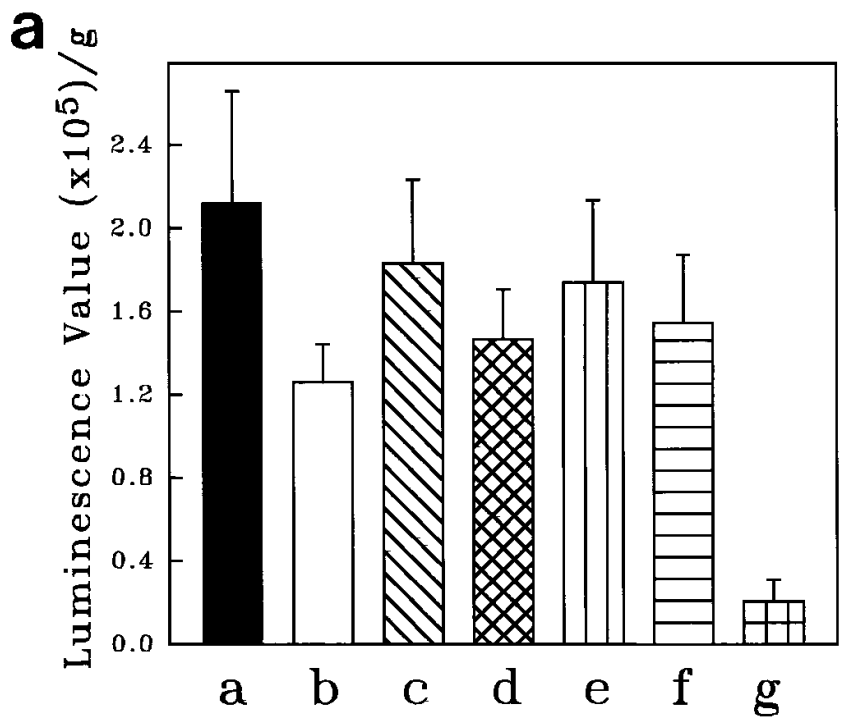

b

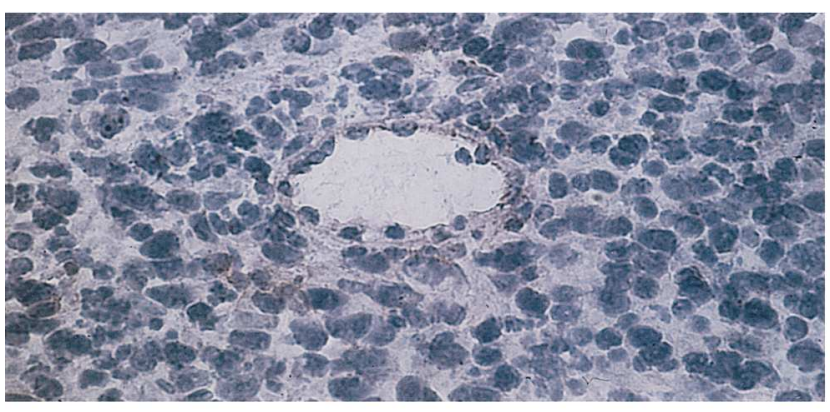

After Gene Transfer

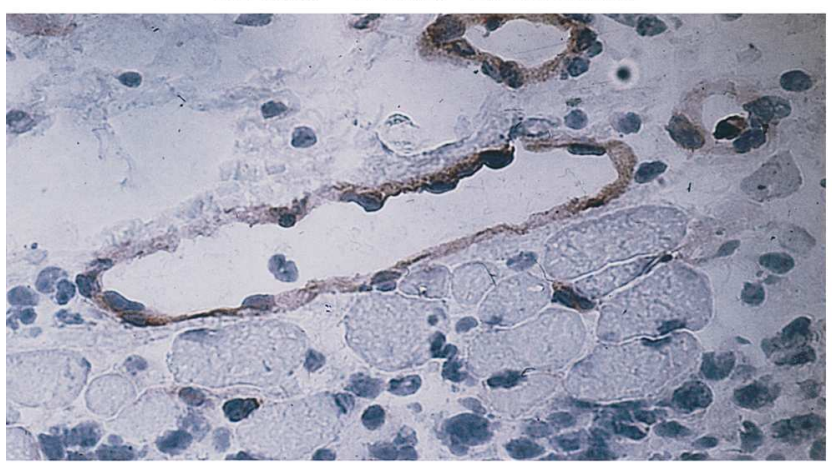

Figure 5. (a) Efficiency of intravenous somatic gene transfer. An expression plasmid containing luciferase cDNA was packed into Lipofectin and injected intravenously (see Methods) into animals with Meth-A sarcomas on days 2 and 7 after the implantation of the tumor. The expression of luciferase was determined enzymatically and quantitated per gram of tissue. The tumor tissue expressed slightly more luciferase per gram of tissue than the other organs. Results are from six animals, bars represent SD. The experiment was repeated two times. A plasmid containing luciferase, but no promoter, was used as negative control. Lane $a$, Meth-A sarcoma; lane $b$, kidney; lane $c$, spleen; lane $d$, liver; lane $e$, lung; lane $f$, heart; lane $g$, control. $n=6$. (b) Intravenous somatic gene transfer leads to expression of the gene product in the tumor vascular endothelial cells. Somatic gene transfer with $\beta$-galactosidase (see Methods) 7 and $2 \mathrm{~d}$ before harvest leads to transfection of endothelial cells in the tumor vascula-

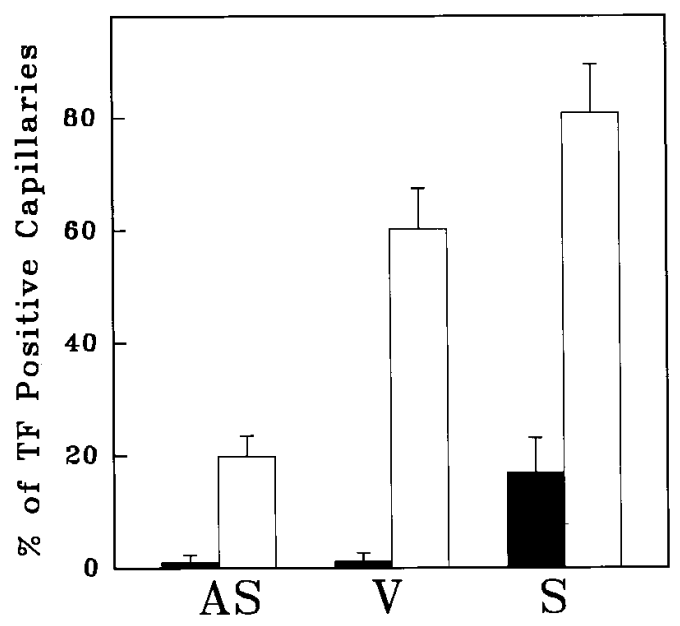

Figure 6. Analysis of tissue factor expression by endothelial cells in tumor capillaries. Tumors were implanted into mice as described in Methods. Tissue factor expression in capillary endothelial cells was evidenced by immunohistochemical staining with rat anti-mouse tissue factor. Tissue factor-positive cells were only regarded as endothelial cells, when counterstaining with anti-von Willebrand factor was positive as well. In each group shown, $>300$ capillaries derived from $n=16$ different animals from two independent experiments were evaluated. Results shown represent the mean \pm SD. Black bars, PBS alone; white bars, PBS + TNF.

most no induction of tissue factor in endothelial cells, in contrast to mice treated with vector (Fig. 4, $a$ and $b$, middle right) or sense (Fig. 4, $a$ and $b$, bottom right).

The effect of intravenous somatic gene transfer on tissue factor expression of tumor capillary endothelial cells was not restricted to the capillaries shown in Fig. 4, $a$ and $b$. When $>300$ capillaries from 16 different animals in each group were evaluated, a clear increase in the number of tissue factor expressing capillaries was seen in sense-treated compared with vector-treated animals, while antisense treatment reduced TNF-mediated tissue factor expression (Fig. 6).

Prevention of tissue factor expression by intravenous somatic gene transfer with an expression plasmid containing tissue factor in the antisense orientation also reduced the amount of fibrin/fibrinogen deposition (Fig. $4 c$, top), compared with vector (Fig. $4 c$, middle) or sense (Fig. $4 c$, bottom).

A marker of activation of the coagulation mechanism is the increase of TAT complexes. To evaluate, whether thrombin formation occurs, we studied TAT formation in tumors $2 \mathrm{~h}$ after injection of TNF (Fig. 7). TNF induced an increase of TAT. TAT was enhanced by intravenous somatic gene transfer with tissue factor sense cDNA and reduced by gene transfer with tissue factor cDNA in the antisense orientation, compared with vector. Thus, tissue factor expression is responsible for the TNF-mediated thrombin and fibrin formation.

A well established consequence of TNF-induced thrombosis is a marked fall in the tumor blood flow. Measurement of tumor blood flow also provides the opportunity to obtain an

ture (immunohistology, peroxidase, $\times 40)$. (Top) A tumor vessel of an animal treated with Lipofectin alone. (Bottom) A tumor vessel after somatic gene transfer with $\beta$-galactosidase. The experiment was repeated two times. 


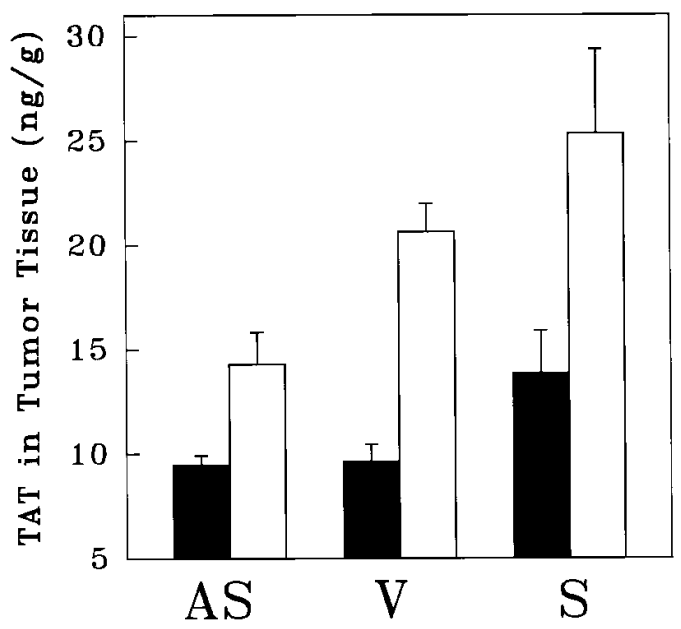

Figure 7. TNF-mediated activation of the coagulation mechanism is tissue factor dependent. Seven mice in each group were implanted with a stable transfected Meth-A transfectant not expressing tissue factor (antisense tissue factor transfectant). After the tumors reached a size of $0.5 \mathrm{~cm}$, intravenous somatic gene transfer was performed with expression plasmids containing tissue factor cDNA (see Methods) in the sense $(S)$ or antisense $(A S)$ orientation. Vector alone $(V)$ served as control. Tumors were taken $2 \mathrm{~h}$ after intravenous injection of $5 \mu \mathrm{g}$ TNF per mouse. TAT was determined as described in Methods. Results shown represent the mean \pm SD. Black bars, control; white bars, TNF.

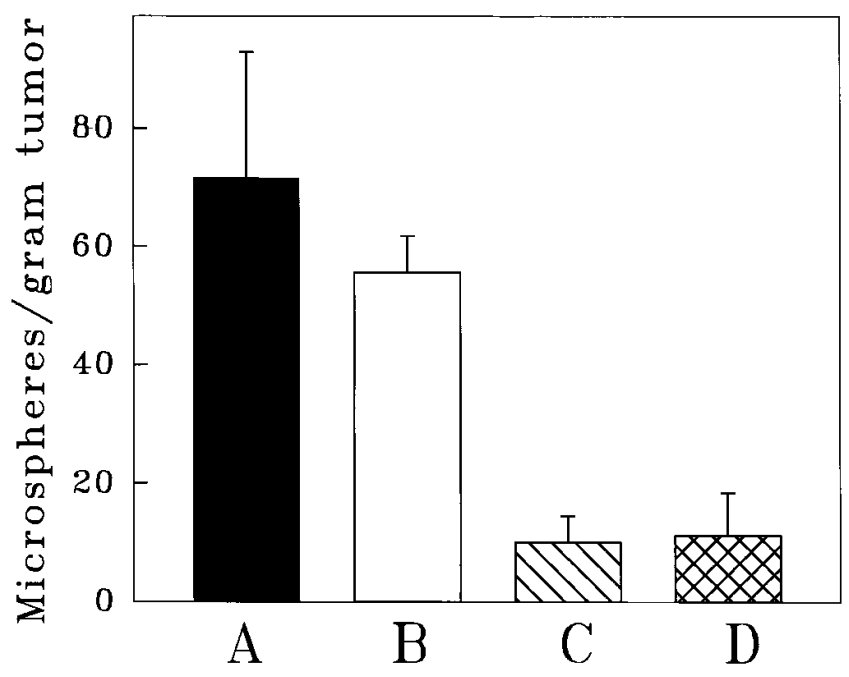

Figure 8. Host tissue factor, but not tumor tissue factor, is responsible for TNF-mediated drop in free blood flow. 10 mice in each group were implanted with a stable Meth-A transfectant not expressing tissue factor (antisense tissue factor transfectant). Free blood flow was evidenced by the number of latex microspheres injected into the left ventricle of the mouse and quantitated as number of beads per gram of tumor tissue. Animals not treated with TNF are shown in black bars. The effect of intravenous somatic gene transfer (see Methods) on the TNF-mediated reduction of free blood flow is shown. Animals treated 7 and $2 \mathrm{~d}$ before TNF with vector alone are depicted in $A$, animals pretreated with the expression plasmid containing tissue factor cDNA in the antisense orientation after TNF are depicted in $B$, animals pretreated with vector alone after TNF are depicted in $C$, and sense tissue factor cDNA pretreated animals after TNF are depicted in $D$. The error bars represent SD. $n=10$. impression of the overall effect of intravenous somatic gene transfer, which is difficult to obtain from immunocytochemistry alone (Fig. 4). We predicted that inhibition of host cell tissue factor expression, blocking thrombus formation, would maintain blood flow to the tumor, based on deposition of latex particles in the vasculature. Mice bearing tumors arising from antisense tissue factor-transfected Meth-A cells were infused intravenously with the plasmid containing tissue factor cDNA in the antisense, sense orientation, or as control with vector alone packed in Lipofectin (Fig. 8). $2 \mathrm{~d}$ after the last gene transfer, mice were treated with TNF under the same conditions as above.

Consistent with our concept, mice with antisense tumors treated with vector alone (Fig. 8, lane $C$ ) showed an $\sim 85 \%$ fall in perfusion after TNF, compared with animals not treated with TNF (Fig. 8, lane $A$ ). The same was observed in animals pretreated with the expression plasmid containing tissue factor cDNA in the sense orientation (Fig. 8, lane $D$ ). To test the hypothesis that the drop in blood flow, evidenced by the number of latex particles, would be dependent on the induction of tissue factor in host cells, we repeated the experiments in mice with impaired expression of tissue factor. When the host mouse was not able to produce tissue factor, due to intravenous somatic gene transfer with the plasmid containing tissue factor cDNA in the antisense orientation, there was almost no fall in blood flow (Fig. 8, lane $B$ ). Thus, the TNF-mediated drop in free blood flow is mainly dependent on tissue factor expressed by host, but not tumor cells.

\section{Discussion}

Studies to examine the effects of cytokines, such as TNF, on cultured endothelium have revealed basic mechanisms likely to underlie the host response to inflammatory stimuli $(5,7,8$, 37). However, extrapolation of these results to the in vivo setting has sometimes been complicated, as exemplified by the induction of tissue factor in endothelium. Although induction of tissue factor in cultured endothelial cells has been demonstrated by many groups, investigation of human atherosclerotic plaques and the vasculature from septicemic animals shows only limited endothelial tissue factor expression outside of the spleen (10-14). Although this could be due, at least in part, to the sensitivity of the assays used, the most logical conclusion is that tissue factor expression in such settings is limited to particular microenvironments, such as the spleen. In this context, our studies in a murine tumor model have delineated another locus in which endothelial cells produce tissue factor, i.e., in tumors. This conclusion is supported by the results of immunocytochemical and in situ hybridization studies showing the presence of tissue factor antigen and mRNA in endothelium in the tumor bed, though very little tissue factor was visualized in vascular beds in the normal organs. Tissue factor expression was most evident in capillaries. The tumor arterioles and venules within the neoplasm displayed only occasional endothelial cells which stained positively for tissue factor. Though such morphological studies are potentially subject to sample bias, our results are representative of the examination of 300 capillaries from 16 tumors in each group of animal studies (Fig. 6). These observations support the hypothesis that TNF-induced expression of endothelial tissue factor does occur in vivo, but is subject to regulation by other elements in the microenvironment. In this context, we have demonstrated pre- 
viously that conditioned medium from Meth-A tumor cells enhances agonist-induced expression of tissue factor by endothelial cells (15), and that this is due to at least three polypeptides made by the tumor $(16,38,39)$.

The second aim of our study was to demonstrate a role for tissue factor on vascular cells in cytokine-induced intravascular activation of the coagulation mechanism in the absence of overt vascular damage, i.e., without denuding vascular injury (15). Intravenous somatic gene transfer with antisense tissue factor constructs, but not with sense tissue factor constructs or vector alone, coordinately reduced the amount of tissue factor synthesized by vascular endothelial cells (Fig. 4, $a$ and $b$, and Fig. 6), and evidence of activation of coagulation in tumor vasculature after infusion of TNF/fibrin/fibrinogen deposition (Fig. 4) and levels of TAT complexes (Fig. 7) were suppressed, and tumor blood flow (Fig. 8) was maintained. In vivo perfusion with large amounts of PBS before histological examination ensures that most nonclotted material (i.e., fibrinogen) has been washed out. The tissue factor responsible for intravascular fibrin formation consequent to administration of TNF in wild-type Meth-A tumors is not likely to arise solely from the neoplastic cells, since stable Meth-A tumor cell transfectants in which tissue factor expression was diminished showed a similar intravascular procoagulant response to TNF (Fig. 2) as tumors derived from control Meth-A cells or Meth-A cell lines overexpressing tissue factor. Based on our data, we believe that endothelial cells are likely to be an important source of tissue factor in the tumor vasculature under these conditions, but a potential contribution of locally activated monocytes/macrophages is also quite likely.

While tissue factor derived from the tumor cells is not necessary for TNF-mediated activation of coagulation in tumor capillaries, tumor-derived tissue factor does have an important role in overall fibrin deposition in the tumor bed. When the time course of fibrin/fibrinogen deposition (Fig. 3) was compared in tumors expressing different levels of tissue factor, there were clear differences. Fibrin/fibrinogen deposition was evident within $30 \mathrm{~min}$ of TNF treatment in tissue factorexpressing Meth-A tumor vasculature. In contrast, after administering TNF to tumors in which tissue factor gene expression was suppressed, there was a lag phase of $>1 \mathrm{~h}$ in fibrin/fibrinogen accumulation (Fig. 3). This delay would be sufficient to allow time for TNF to trigger biosynthetic mechanisms resulting in tissue factor gene expression, translation, and expression of the protein in active form. These data also emphasize another facet of TNF-induced activation of intravascular coagulation. The rapid fibrin formation in wild-type Meth-A tumors (i.e., within $30 \mathrm{~min}$ ) is likely to reflect mechanisms initiated by TNF which allow exposure of preformed tissue factor its enzyme and substrate. This could result from a rapid changing vascular barrier function. For example, TNF has been shown to increase vascular permeability (40-42), thereby allowing plasma coagulation components enhanced access to the subendothelial space. In vivo, the situation could be more complex due to TNF-induced activation of multiple cell types. TNF-mediated stimulation of polymorphonuclear leukocytes could promote their deposition in tumor vasculature with subsequent damage to the endothelium by released enzymes and reactive oxygen intermediates. Other mechanisms by which TNF could rapidly influence the cellular disposition or activity of tissue factor could involve an effect on translocation of the apoprotein to the cell surface or the phospholipid milieu into which the tissue factor is inserted. Although both types of mechanisms are possible, we favor the involvement of TNFinduced mechanisms perturbing vascular barrier function, as this would be consistent with administration of TNF (40-42).

These data emphasize the multiple events which underlie TNF-induced activation of the procoagulant pathway in tumor vasculature. In the absence of TNF, even when there was increased expression of tissue factor in the intravascular space, as occurred in animals treated with tissue factor cDNA in the sense orientation, there was at most only a slight enhancement of fibrin/fibrinogen deposition (Fig. 4). This might be explained by the low efficiency of intravenous gene transfer, a nonoptimal lipid environment of the endothelial cell membrane for efficient VIIa binding and activation of Factors IX and $\mathrm{X}$, or by the requirement of other blood cells (monocytes) for optimal fibrin formation. This endothelial tissue factor might be present at a cryptic site, probably sequestered in the basal cell surface or subendothelial matrix $(43,44)$, with respect to its function as a procoagulant cofactor. Addition of TNF rapidly triggers additional mechanisms rendering tissue factor a potent activator of the coagulation mechanism. Such mechanisms are likely to involve TNF-induced changes in vascular permeability and cell-cell interactions, as well as further augmentation of tissue factor synthesis.

\section{Acknowledgments}

This work was supported by a grant from the Deutsche Forschungsgemeinschaft (Na 138), Thyssen-Stiftung and Mildred Scheel Foundation. P. Nawroth performed this study during the tenure of a Heisenberg Stipend (DFG). D. Stern was supported by grants HL42833 and HL42507.

\section{References}

1. Bach, R.R. 1988. Initiation of coagulation by tissue factor. Crit. Rev. Biochem. 23:339-348.

2. Andree, H., and Y. Nemerson. 1995. Tissue factor: regulation of activity by flow and phospholipid surfaces. Blood Coagul. \& Fibrinolysis. 6:189-197.

3. Weiss, H.J., and B. Lages. 1988. Evidence for tissue factor dependent activation of the classic extrinsic coagulation mechanism in blood obtained from bleeding time wounds. Blood. 71:629-635.

4. Taylor, F.B., Jr., A. Chang, W. Ruf, J.H. Morrissey, L. Hinshaw, R. Catlett, K. Blick, and T.S. Edgington. 1991. Lethal E. coli septic shock is prevented by blocking tissue factor with monoclonal antibody. Circ. Shock. 33:137134 .

5. Beutler, B., I.W. Milsark, and A.C. Cerami. 1985. Passive immunization against cachectin/tumor necrosis factor protects mice from the lethal effects of endotoxin. Science (Wash. DC). 229:869-871.

6. Conway, E.M., R. Bach, R. Rosenberg, and W.H. Konigsberg. 1989. Tumor necrosis factor enhances expression of tissue factor mRNA in endothelial cells. Thromb. Res. 53:231-241.

7. Bevilacqua, M.P., J.S. Pober, G.R. Manjeau, W. Fiers, R.S. Cotran, and M.A. Gimbrone. 1986. Recombinant tumor necrosis factor induces procoagulant activity in cultured human vascular endothelium: characterization and comparison with the action of interleukin-1. Proc. Natl. Acad. Sci. USA. 83: 4533-4537.

8. Nawroth, P.P., and D.M. Stern. 1986. Modulation of endothelial cell hemostatic properties by tumor necrosis factor. J. Exp. Med. 163:740-745.

9. Bierhaus, A., Y. Zhang, Y. Deng, N. Mackman, P. Quenhengerger, T. Sernau, M. Haase, T. Luther, J. Greten, P. Bäuerle, et al. 1995. Mechanism of the tumor necrosis factor $\alpha$-mediated induction of endothelial tissue factor. $J$. Biol. Chem. 270:26419-26432.

10. Drake, T.A., J.H. Morrissey, and T.S. Edgington. 1989. Immunohistochemical detection of tissue factor in human arteriosclerotic plaques. Circulation. 80:181-189.

11. Wilcox, J.N., K.M. Smith, S.M. Schwartz, and D. Gordon. 1989. Localization of tissue factor in the normal vessel wall and in the atherosclerotic plaque. Proc. Natl. Acad. Sci. USA. 86:2839-2843.

12. Drake, T.A., J.H. Morrissey, and T.S. Edgington. 1989. Selective cellu- 
lar expression of tissue factor in human tissue: implications for disorders of hemostasis and thrombosis. Am. J. Pathol. 134:1087-1097.

13. Drake, T.A., J. Cheng, A. Chang, and F.B. Taylor, Jr. 1993. Expression of tissue factor, thrombomodulin, and E-selectin in baboons with lethal Escherichia coli sepsis. Am. J. Pathol. 142:1458-1470.

14. Mackman, N., M.S. Sawdey, M.R. Keeton, and D.J. Loskutoff. 1993. Murine tissue factor gene expression in vivo. Tissue and cell specificity and regulation by lipopolysaccharide. Am. J. Pathol. 143:76-84.

15. Nawroth, P.P., D. Handley, G. Matsueda, R. De Waal, H. Gerlach, D. Blohm, and D. Stern. 1988. Tumor necrosis factor/cachectin-induced intravascular fibrin formation in Meth A fibrosarcomas. J. Exp. Med. 168:637-647.

16. Clauss, M., C. Murray, V. Vianna, R. deWaal, G. Thurston, P. Nawroth, H. Gerlach, R. Bach, P.C. Familetti, and D.M. Stern. 1990. A polypeptide factor produced by fibrosarcoma cells that induces endothelial cell tissue factor and enhances the procoagulant response to tumor necrosis factor/cachectin. $J$. Biol. Chem. 265:7078-7083.

17. Zhang, Y.M., Y.H. Deng, T. Luther, R. Waldherr, D.M. Stern, R. Ziegler, and P.P. Nawroth. 1994. Tissue factor controls the balance of angiogenic and antiangiogenic properties of tumor cells in mice. J. Clin. Invest. 94:1320-1327.

18. Boutler, C.A., and E.F. Wagner. 1987. A universal retroviral vector for efficient constitutive expression of exogenous genes. Nucleic Acids Res. 17: 7194.

19. Keller, G. 1985. Expression of a foreign gene in myeloid and lymphoid cells derived from multipotent haematopoietic precursors. Nature (Lond.). 318: $149-154$

20. Scharfmann, R., H.A. Jonathan, and M.V. Inder. 1991. Long-term in vivo expression of retrovirus-mediated gene transfer in mouse fibroblast implants. Proc. Natl. Acad. Sci. USA. 88:4626-4630.

21. Hartzell, S., K. Ryder, A. Lanahan, L. Lau, and D. Nathans. 1989. A growth factor responsive gene of murine $\mathrm{BALB} / \mathrm{c} 3 \mathrm{~T} 3$ cells encodes a protein homologous to human tissue factor. Mol. Cell. Biol. 9:2567-2573.

22. Felgner, P.L., T.R. Gadek, M. Holm, R. Roman, H.W. Chan, M. Wenz, J.P. Northrop, G.M. Ringold, and M. Danielsen. 1987. Lipofectin: a highly efficient, lipid-mediated DNA-transfection procedure. Proc. Natl. Acad. Sci. USA. 84:7413-7418

23. Nawroth, P.P., D.M. Stern, W. Kisiel, and R. Bach. 1985. Cellular requirements for tissue factor generation by bovine aortic endothelial cells in culture. Thromb. Res. 40:677-691.

24. Southern, E.M. 1975. Detection of specific sequences among DNA fragments separated by gel electrophoresis. J. Mol. Biol. 98:503-517.

25. Thomas, P.S. 1980. Hybridization of denatured RNA and small DNA fragments transferred to nitrocellulose. Proc. Natl. Acad. Sci. USA. 77:52015314.

26. Greenberg, M.E., and E.B. Ziff. 1984. Stimulation of 3 T3 cells induces transcription of the c-Fos protooncogene. Nature (Lond.). 311:433-438.

27. Polak, J.M., and S. Van Noorden. 1983. Immunocytochemistry: Practical Applications in Pathology and Biology. John Wright and Sons Ltd., Littleton, MA.

28. Alam, J., and J.L. Cook. 1990. Reporter genes: application to the study of mammalian gene transcription. Anal. Biochem. 188:245-256.

29. Ow, D., K. Wood, M. DeLuca, J. Wet, D. Helinski, and S. Howell. 1986.
Transient and stable expression of the firefly luciferase gene in plant cells and transgenic plants. Science (Wash. DC). 234:856-868.

30. Echtenacher, B., W. Falk, D.N. Mannel, and P.H. Krammer. 1990. Requirement of endogenous tumor necrosis factor/cachectin for recovery from experimental peritonitis. J. Immunol. 145:3762-3770.

31. Nilsson, B.O., and A. Larsson. 1990. Intrasplenic immunization with minute amounts of antigen. Immunol. Today. 11:10-16.

32. Single, R.H., and D.C. Ward. 1982. Actin gene expression visualized in a chicken muscle tissue culture by using in situ hybridization with a biotinylated nucleotide analog. Proc. Natl. Acad. Sci. USA. 79:7331-7335.

33. Larsson, L.I. 1988. Immunocytochemistry: Theory and Practice. CRC Press, Inc., Boca Raton, FL. 95.

34. Kaplow, L.S. 1974. Cytologic studies of hematopoietic cells by interference contrast (Nomarski) optics. Am. J. Clin. Pathol. 63:451-456.

35. Zhang, Y.M. S. Bachmann, C. Hemmer, J. van Lunzen, A. von Stemm, P. Kern, M. Dietrich, R. Ziegler, R. Waldherr, and P.P. Nawroth. 1994. Vascular origin of Kaposi's sarcoma: expression of leukocyte adhesion molecule-1, thrombomodulin, and tissue factor. Am. J. Pathol. 144:51-59.

36. Ritthaler, U., Y. Deng, Y. Zhang, J. Greten, M. Abel, B. Sido, J. Allenberg, G. Otto, H. Roth, A. Bierhaus, et al. 1995. Expression of receptors for advanced glycation end products in peripheral occlusive vascular disease. Am. J. Pathol. 146:688-694.

37. Nawroth, P.P., I. Bank, D. Handley, J. Cassimeris, L. Chess, and D. Stern. 1986. Tumor necrosis factor interacts with endothelial cell receptors to induce release of IL-1. J. Exp. Med. 163:1363-1375.

38. Clauss, M., M. Gerlach, H. Gerlach, J. Brett, F. Wang, P.C. Familletti, Y.-C. E. Pan, J. V. Olander, D. T. Connolly, and D. Stern. 1990. Vascular permeability factor. A tumor-derived polypeptide that induces endothelial cell and monocyte procoagulant activity, and promotes monocyte migration. J. Exp. Med. 172:1535-1545.

39. Kao, J., J. Brett, G. Godman, J. Chen, P. Familletti, J. Wang, Y.-C. Pan, D. Stern, and M. Clauss. 1992. Endothelial-monocyte activating polypeptide II a novel tumor-derived polypeptide which activates host-response mechanisms. J. Biol. Chem. 267:20239-20247.

40. Brett, J., H. Gerlach, P. Nawroth, S. Steinberg, G. Godman, and D. Stern. 1989. TNF increases permeability of endothelial cell monolayers by a mechanism involving regulatory G protein. J. Exp. Med. 169:1977-1991.

41. Clark, M., M.-J. Chen, S. Crooke, and J. Bomalasaki. 1988. TNF induces phospholipase A2-activating protein in endothelial cells. Biochem. J. 250:125134

42. Camussi, G., E. Turello, F. Russolino, and C. Baglioni. 1991. TNF alters cytoskeletal organization and barrier function of endothelial cells. Int. Arch. Allergy Appl. Immunol. 96:84-91.

43. Ryan, J., J. Brett, P. Tijburg, R. Bach, W. Kisiel, and D. Stern. 1992. Tumor necrosis factor induced endothelial tissue factor is associated with subendothelial matrix vesicles but not expressed on the apical surface. Blood. 80:966974

44. Maynard, J., C. Heckman, F. Pitlick, and Y. Nemerson. 1976. Association of tissue factor activity with the surface of cultured cells. J. Clin. Invest. 55 814-824. 